\title{
Criminal Justice Responses and Fear of Crime in the Era of COVID-19
}

\author{
Chyna N. Crawford, PhD*
}

\begin{abstract}
While COVID-19 might be a new viral strand, many of the problems it has triggered in the criminal justice system are complications we have seen before. The COVID-19 pandemic crisis has amplified the issues of fear of crime, prison over population, and issues regarding non-violent crimes that exist within the United States. Statistics show that those who are incarcerated in America include high numbers of elderly, sick and at-risk inmates, and high rates of non-violent/ pretrial populations, which leads to prisons becoming hotspots for coronavirus. The scientific community has come to the agreement and made recommendations that prisons and jails need to be depopulated to prevent further spread; however, to date, the types of offenders released is disproportional and the number of people released has remained minimal, resulting in explosive outbreaks of COVID-19 behind bars. Since the depopulation of correctional settings is also rarely paired with meaningful efforts to reform and reduce the non-violent prison population, this paper will examine how the criminal justice system has responded to Coronavirus crisis to date; how the fear of crime outpaces fear of disease; and how this data can contribute to the nation's reformation of the criminal justice system.
\end{abstract}

Keywords: COVID-19, coronavirus, criminal justice responses, pandemic, criminal legal system, incarceration, non-violent offenders, release, prison, jail, returning, quarantine

*Dr Chyna N. Crawford is an Assistant Professor of Criminal Justice and Chairperson of the Department of Social Sciences at Elizabeth City State University, Elizabeth City, North Carolina, USA. 


\section{Criminal Justice Responses and Fear of Crime in the Era of COVID-19}

\section{Introduction}

In the past few decades in the United States, fear of crime has not decreased considerably, despite decrease in violent crime rates. This has led researchers (Freckelton, 2020). to theorize that fear of crime may be influenced by factors beyond local crime rates. As a result of disproportionate suspicions about violent crime and unreliable crime assessments, the true risk of victimization could be overestimated (Reichert \& Konefal, 2016). Residents are often unaware of the actual prevalence of crime in their community and their perceptions may be based on neighborhood characteristics, vicarious victimizations (i.e., witnessing a crime or knowing someone who has been a victim of a crime), and misconceptions about their neighborhood's crime problems relative to other neighborhoods. Unwarranted negative perceptions and fear may be harmful to residents, contributing to depression and anxiety (Freckelton, 2020).

As of April 2020, according to Gallup (Saad, 2020), the majority of Americans (57\%) were worried about getting COVID-19. These findings are based on a probability-based sample of 2,448 U.S. adults from the Gallup Panel, interviewed by web April 10-12, 2020. By early October, after contracting COVID-19 and being treated at Walter Reed Medical Center, President Trump stressed and downplayed effects of COVID-19, stating "Don't be afraid of COVID. Don't let it dominate your life"to the American people (Moneymaker, 2020).

Although public health and economic programs have received the most attention with regards to the impact of COVID-19, substantial attention should also be given to the effect of COVID-19 on America's criminal justice system, and especially its approach to pretrial detention, and the high numbers of incarcerated sick and elderly. The United States incarcerates more prisoners per capita than any developed nation in the world. But what most Americans do not know is that 462,000 out of 2.3 million, 20 percent of persons imprisoned in the United States are locked up in local prisons only waiting for their day in court(Surprenant, 2020). They were not convicted of anything. As the courts have shut down, COVID-19 has made this already-bad situation worse. Overcrowded jails act as infection hotbeds(Surprenant, 2020). In the long term, changes such as reducing the number 
of offenses requiring jail booking, removing cash bail, and fostering alternatives to jail are important, even as local law enforcement is acting to change the situation in the short term.

This paper seeks to examine how the criminal justice system has responded to Coronavirus crisis to date; how the fear of crime overtakes fear of disease; and how this data can contribute to the nation's reformation of the criminal justice system.

\section{COVID-19 in the United States}

Coronavirus or COVID-19 is novel virus. The COVID-19 infection spreads from individual to individual through the air when somebody who is sick coughs or sneezes, or through close intimate contact like touching or shaking hands. It likewise could spread if someone encounters an item with COVID-19 on it and, at that point makes contact with their mouth, nose or eyes (Centers for Disease Control [CDC], 2020). Because of the highly communicable nature of COVID-19, social distancing recommendations were put in place across the nation. The most ideal approach to stop the spread of this illness is by staying at least six feet from others or practicing social distancing (CDC, 2020). These distancing recommendations the COVID-19 pandemic led to substantial changes in the daily activities of millions of Americans, with many businesses and schools closed, public events cancelled and states introducing stay-at-home orders.

The Centers for Disease Control (2020) calculate that there are as many as 160 to 214 million individuals, in the United States, who could contract coronavirus (SARS-CoV-2, which triggers the COVID-19 disease). Their early estimates also noted that COVID-19 could kill as many as 200,000 to 1.7 million people. As of October 2020, the rates of death have surpassed 200,000 people, and continue to increase (Nowotny, Bailey, Omori, 2020).

While COVID-19 might be a new viral strand, many of the problems it has triggered in the criminal justice system are complications we have seen before. The COVID-19 pandemic crisis has amplified the issues of fear of crime, prison over population, and issues regarding non-violent crimes that exist within the United States(Burki, 2020). The scientific community has come to the agreement and made recommendations that prisons and jails need to be depopulated to prevent 
further spread (Burki,2020; Akiyama, Spaulding, \& Rich, 2020; Surprenant, 2020)however, to date, the types of offenders released is disproportional and the number of people released has remained minimal, resulting in explosive outbreaks of COVID-19 behind bars.

Although some correctional institutions have accepted the need, many others are resistant to changes. This crisis reiterates the need for progressive changes in criminal justice policy, and broader implementation of compassionate release, and the abolition of cash bail, in particular, has shown that legislative reform is needed. COVID-19 case rates in jails have been significantly higher and rising even more rapidly than in the US population. In jails, the COVID-19 case rate was initially lower but on April 14, 2020, its rates exceeded the US population. The mean daily average rate of case growth in jails was $8.3 \%$ per day, whereas the Population in the US was $3.4 \%$ per day (Saloner, Parish,Ward,DiLaura,Dolovich, 2020).Immediate intervention would have had a beneficial effect on slowing the spread of COVID-19 and should become common procedure in order to mitigate the health damage caused by mass incarceration (Reinhart, \& Chen, 2020).

\section{COVID-19 in Correctional Facilities}

Jails (which house people awaiting trial or serving short sentences) and prisons (which house people convicted of crimes and serving sentences of one year or more) are typically crowded. The United States has detained more people than any other nation on Earth because of mass incarceration policies over the past four decades. In our culture, individuals entering prisons are among the most vulnerable, and during incarceration, restricted mobility, small spaces, and restricted medical care worsen the vulnerability (Akiyama, Spaulding, \& Rich, 2020). Many people held in municipal jails are there for violent crime, property crime, public-order crime, and breaches of parole and probation. The statistics related to violations of parole and probation are particularly surprising, comprising 45 percent of all local jail admissions. More than half of these arrests/ detentions are technical violations. Which is conduct by an offender under supervision that is not by itself a criminal offense (i.e., failing to report for a scheduled office visit, missing a curfew, or testing positive for drug or alcohol) (Surprenant, 2020). This means that more than 25\% of all jail admissions, a staggeringly high number, are for non-criminal offices, which generally would not result in an arrest, however, because of their probation/parole status they now face reimprisonment (Surprenant, 2020). 
If they are unable to comply with the steps needed to control and prevent a viral outbreak, incarcerated people, workers, and the broader community are at risk (Hawks, Woolhandler, \& McCormick, 2020). Similarly, the infrastructure of most prisons and jails are conducive to the spread of illness. People involved in the justice system in the United States already have been affected by the severe acute respiratory syndrome coronavirus 2 (SARS-CoV-2) at much higher rates than the general population. Because of this increased preparedness is necessary in order to minimize the effects of this pandemic on inmates, correctional workers and local communities (Akiyama, Spaulding, \& Rich, 2020).

Beyond COVID-19, the established, social and service conditions in jails and prisons amplify health risks. While correctional facilities face hazards that are comparable to those of for community health care, larger correctional environments, show social distancing as being highly difficult. According to the U.S. Department of Justice (2020) 81,600 inmates are over 60 years of age, in addition, half of all those imprisoned have at least one chronic illness, a variable that raises the likelihood of bad infection outcomes (U.S. Department of Justice, 2020) In order to care for a disabled and elderly populace, correctional facilities regularly lack the required levels of skilled personnel. Such facilities are often overcrowded, have no airflow and have little to no access to healthcare. Even when soap is issued, compliance with the fundamental recommendation of regular handwashing is difficult and counterproductive when insufficient supplies of soap have to be shared, and when inmates have to purchase additional supplies (Nowotny, Bailey, Omori, Brinkley- Rubinstein 2020). Most jails also limit access to hand sanitizer, which contains Alcohol, for fear it will be used nefariously by inmates (Wurcel et. al,, 2020). In addition, persons who are imprisoned would also be at greater risk of exposure, as correctional officers and other personnel exit the building and return afterwards. Social distancing is typically a physical challenge in prisons and jails. Older people, and individuals with underlying conditions, are at high risk of serious complications to COVID-19 disease and mortality. The total age of the prison population has risen because of longer sentences, mostly due to the increased number of non-violent offenders (Hawks, Woolhadnler, \& McCormick, 2020).

Few prisons in the United States have health care facilities capable of accommodating a spike in sick inmates. The obstacles to adequate health care found in prison environments are compounded 
by crowding and clinical vulnerability. Even though the US Constitution guarantees people who are imprisoned a right to health care, affordable medical care differs greatly in terms of access and efficiency, and programs have been questioned by the increased needs of the elderly population in jail. While these steps are necessary, the most successful way to prevent an imminent outbreak is to avoid them (Hawks, Woolhadnler, \& McCormick, 2020).

The Federal Bureau of Prisons (BOP) housed approximately 126,127 federal inmates in BOPmanaged institutions as of early October 2020 and 14,320 in community-based facilities. The number of BOP personnel is approximately 36,000. At that time, there were 1,539 federal prisoners and 719 BOP staff who have confirmed national positive test results for COVID-19. At present, 13,733 inmates and 1,211 employees had recovered. Directly linked to COVID-19 illness, there have been 125 federal inmate fatalities and 2 BOP staff member fatalities. Of the prisoner fatalities, 4 occurred during home confinement (Bureau of Prisons, 2020a).To assist in slowing transmissions inside a correctional setting, the BOP has started additional monitoring of asymptomatic inmates. As such, BOP data represents an improvement in the number of positive COVID-19 tests. The BOP can make better use of this data for the management of an outbreak at the relevant facility affected.Inmates enrolled in the Federal Location Tracking program, inmates supervised under the USPO, or being held in privately run prisons are not included in the inmate totals reported.

\section{Decarceration vs. Inmate Isolation}

Social Distancing has been the most often means of mitigation outside of prison walls. Hundreds of thousands of susceptible individuals are at increased risk of serious illness with a restricted capacity to defend themselves and others by self-isolating.Within correctional institutions Social isolation is associated with negative mental health outcomes (Arrigo \& Bullock, 2008; Haney, 2012).

It is also risky to promote the widespread use of isolation to minimize the spread of COVID-19, as it could worsen symptoms of mental wellbeing, self-injury, and suicide (Henry, 2020). If incarcerated persons have fair access to quality preventive and recovery services for COVID-19, 
health equality can be achieved (Akiyama, Spaulding, \& Rich, 2020). The Federal Bureau of Prisons, and some counties and state Municipalities have opted to cancel group visits, restrict legal representatives' visits, and decrease facility transfers for people imprisoned. To decrease social alienation and to minimize some correctional institutions offer teleconferencing facilities for imprisoned persons to retain a level of accessibility (Akiyama, Spaulding, \& Rich, 2020).

Sheriffs and district attorneys around the nation are acting on the go to try to reduce the risk of SARS-CoV-2 outbreaks in local jails in response to these concerns. Many law enforcement agencies have embraced "cite and release" strategies for offenses that would have resulted in detention prior. Most dramatically, in hopes of decreasing their inmate numbers to stop an increase infection transmittal, many states and counties have discussed the release of thousands of "lowlevel offenders" from their facilities. The short-, medium-, and long-term solutions to the current challenges of transmitting COVID-19 and possible infectious diseases are mostly centered on reducing the number of people detained in local prisons. There are a number of significant measures that policymakers should take to achieve this goal, all of which are now politically palatable and continue to develop as the two-fold public health and economic crisis unfolds (Surprenant, 2020).

As others have argued (Surprenant, 2020;Hawks, Woolhadnler, \&McCormik, 2020;(Henry, 2020) the population of jails and prisons needs to be significantly decreased. To decrease prison admissions and the duration of stays, some prosecutors are already changing prosecutorial standards. In some jails, these measures may decrease crowding, but many other jails and most prisons are minimally affected inhabitants (Hawks, Woolhadnler, \&McCormik, 2020). Incarcerating elderly people, however, does nothing to improve public safety, and recidivism is much lower at older ages than it is at younger ages. The greater concern is to ensure that sufficient care for elderly people is in place after they are released from prison, since they have undoubtedly spent decades behind bars and, thus, have minimal or non-existent networks of social support (Henry, 2020).

For example, in early April, California set a statewide emergency bail schedule that reduced bail to $\$ 0$ for most misdemeanor and some low-level felony offenses (Smith, 2020). Since then, 
California jail populations have dropped. By late may, inmate populations in Los Angeles County (Scott, 2020) and Sacramento County (Pohl, 2020) had declined by more than 30\%. Orange County's prison population fell by almost $45 \%$ in the same period, while other counties including San Diego, San Mateo, and Stanislaus (Moran, 2020) - also released hundreds of pretrial inmates. The Judicial Council voted to end this nationwide emergency bail schedule in June, but 31 counties (collectively about 80 percent of California residents) have opted to keep the emergency bail schedule in place (Balassone, 2020; Bradshaw, 2020).

Similarly, in Massachusetts following an order provided by the Supreme Court in early April 2020, the release of persons held in pre-trial custody for "non-violent" offences and those held for technical probation and parole breaches was authorized (Souza, 2020a; Bentley, 2020; Souza, 2020b). Because of that order, both Plymouth County and Norfolk County jail facilities have decreased their populations by about 20\% (Souza, 2020a; Bentley, 2020). Meanwhile, an additional facility in Bristol County, has decreased their population has by 11 per cent since the April 2020 order (Souza, 2020b).

Decarceration makes it possible for certain restricted persons to return to their families and access community services that are typically of better quality than those in jail. It also decreases the population of incarcerated individuals, allowing for greater social distancing and increased access to the limited services available. Decarceration means minimizing the influx of individuals to prisons and speeding up the flow of individuals from prisons by minimizing arrests and increasing early release (Akiyama et al., 2020; Henry, 2020). With citations and other non-carceral alternatives, arrests may be substituted. Early release populations with readily available policies include persons held pre-trial on cash bail, eligible for probation / community monitoring release, and eligible for medical / compassionate release (Henry, 2020).

The decision to not decarcerate, is a purely political policy decision that deliberately encourages high rates of new COVID-19 infections, and eventually deaths, in an already vulnerable and marginalized population. Policymakers inevitably expose incarcerated individuals to even higher risks of COVID-19 contamination by preferring isolation (Henry, 2020). At a time when more new cases of coronavirus are identified on a regular basis, state and local governments should intensify 
their efforts to minimize the number of people in prisons and jails, where social distancing is difficult and there is a continuous cycle of people in and out of the facility.

Likewise, pretrial incarceration is connected to a greater risk of reoffending, since people's networks are destabilized (Nowotny, Bailey, Omori, Brinkley- Rubinstein, 2020). Initial countylevel work suggests that the vast majority of released individuals will appear without a financial incentive for their court date and that when individuals do not appear, it is typically for nonfinancial reasons, such as lack of travel, sickness, or failure to leave work or find childcare(Nowotny, Bailey, Omori, Brinkley- Rubinstein, 2020).

Prosecutors in Brooklyn, New York (Denney \& Celona , 2020) and Philadelphia, Pennsylvania (Melamed \& Newall, 2020) took action in mid-March to limit prison admissions by releasing people charged with non-violent crimes, and not actively pursuing low-level, non-violent crimes. Lowering prison/ jail enrollment decreases the rapid flow of people in and out of facilities. This practice would cause the overall population of the institution to decline very rapidly. Reducing prison/jail admissions decreases the risk of infectious transmission of COVID-19 into the prison populations and helps to maintain a size of the prison population with which adequate medical services can be given by the institution. Unsurprisingly, as of October 2020, prisons have released almost no one, especially when compared to local jails, as discussed by Prison Policy Initiative (2020a). State prison facilities, however, are rife with inmates with re-existing and underlying medical conditions that place them at increased risk of complications from a COVID-19 infection. So far, in the face of the pandemic, some states have taken action to reduce the prison population. Critics note that these steps would put members of the community in danger. However actual crime data suggest crime rate would lower, and those released would be less likely to recidivate than younger or violent offenders (Franco-Paredes, 2020). However, the most recent data analysis from hundreds of counties across the nation shows that efforts to reduce incarcerated populations have slowed and even reversed in some places as of August 2020(Prison Policy Initiative, 2020b). According to the data from 668 jails analyzed by PPI (2020b), 71 percent of the facilities had population increases from May to July2020 and 84 institutions had increased incarceration rates to above the reported numbers in March. 


\section{COVID-19 and Crime in Communities}

Official crime data comes from law enforcement authorities, so it is a database of crimes reported to, or by, police. When policing activities, thus, change, so do crime statistics. This pandemic has affected police forces in a variety of ways: police officers have gotten ill, and authorities have instructed police to avoid unwanted interaction with the public and even to respond to certain crimes differently, such as issuing citations in lieu of arrest. Most of these improvements have ledto less recorded incidents, as less police officers are available to patrol the streets, less traffic and street stops face-to-face, and less arrests overall. So, some of the "decrease" in crime is due to police changes rather than criminal activity changes.

\section{COVID-19 and Crime}

An analysis of the impact of the coronavirus (COVID-19) lockdown has shown a decrease in almost all areas of crime recorded by police. Since the beginning April 2020, crime rates have fallen, with most of the country under "stay at home" orders. Cities around the country have seen improvements in crime rates as well as in the number of total crimes recorded (PPI, 2020, Adams, 2020). Changes in the forms of type of crime and locations of crimes are among the crime patterns reported during this pandemic. Violent crime has declined, notably, and burglaries have now switched away from home break-ins to strike closed firms. In a world where more people stay home during working hours and on weekends, these shifts make sense, and most brick-and - mortar firms are either closed or running fewer hours and only a fraction of their regular workers. People have to come into close contact for violent crimes like assault or theft to occur.

More troubling changes are happening, potentially fueled by the emotional pressure of social distancing and mutual distress, not to mention the economic pressure of millions of people 's sudden loss of income. Some cities have reported an uptick in domestic violence-related calls, for instance, and children are more vulnerable to abuse and neglect at home with schools closed. We will see more internet-based white-collar crime, such as the new crop of scams identified by the FBI, with trade moving largely online. 


\section{Fear of Crime}

In criminology, we talk a lot about fear. More specifically, we focus on how our political, legislative, economic and socio-cultural structures establish situations in which, more than others, we fear certain persons or certain events. Fears are built. They dictate what we are criminalizing, or how we wish to control, police, judge, or imprison. Fears can provide a shield for racial, biased and undermining procedures for crime and justice responses.

For a long time, states and industries have been skilled at mobilizing fears. Slavery, racial brutality, deprivation of treatment, mass imprisonment, oppressive border barriers, and other activities, have been quickly operational, commodified, and legitimized by fears. As reactions to larger social issues, police and protection are frequently over-emphasized, Fear-based reactions largely revolve around separation or in the case of the U.S. incarceration (Freckelton, 2020). The protective measures used are also noticeable in the armed patrolling in targeted neighborhoods, the construction in gated communities, the introduction of emerging population security monitoring systems, the withdrawal of economic or other assistance from others perceived as 'not us' or by the number of persons incarcerated. What we are witnessing during this pandemic, is that anxiety takes on new definitions. People are now not only concerned about a virus that is impossible to see, hard to manage, which spreads by physical closeness. Pandemics generate fear, anxiety and paranoia that can lead to a number of undesirable community phenomena, including discrimination, scapegoating and predation on the vulnerable (Freckelton, 2020).

Fears are also evident in other sectors. President Trump alleged that an American left-orchestrated "anti-police crusade" has led to a "shocking surge of assaults, attacks, murders, and heinous violent crimes" (Pascrell, 2020). He proclaimed on July 22 that he would send an influx of federal agents to assist local police (Pascrell, 2020). But the data suggests that America is facing a significant wave of crime is mixed at best. While official national crime figures may not arrive for another year, Abrams (2020) show that overall crime has actually fallen by about 10 percent so far this year compared to the same period in 2015-1919. Though the questions remain, which issue has American citizens more fearful; COVID-19 or long held, semi irrational fears of crime. 
For example, it is clear that the pandemic requires multiple measures to ensuring that public welfare is prioritized by our justice system. More than ever, in institutions such as jails that are extremely vulnerable to infectious contamination and lack meaningful access to health care, we need to stop excessive detention of individuals. An inability to do so would ultimately fuel anxieties and damage within the correctional domain as well as illnesses throughout all group environments (Freckelton, 2020).

Unfortunately, there is little evidence showing that mass incarceration has ensured public safety. Correctional services have been turned into counter-productive facilities that exacerbate racial inequities through the social and economic costs of relying on excessive incarceration and the inability to resolve the key causes of crime (Franco-Paredes et.al., 2020).

\section{Recommendations}

Public health emergencies often carry long-standing concerns to the forefront. The injustice, and responses due to the pandemic of COVID-19 is not an exception to the rule. At present, examples of different consequences for different population groups can be seen. One such community is imprisoned people, leading advocates of criminal justice reform and public policy experts to sound the bell that many others have for changes. Calling for the promotion of social, and racial justice and health disparities for years. While The country has attempted to make great strides over the decades. We are not out of the woods yet, we ought to press for a long-term, bold transformation of our criminal-legal system that prioritizes communityhealth and equity.

For those who will remain incarcerated, in order to promote and increase COVID-19 mitigation policies in prisons, the list of guidelines below has been complied (Wurcel, 2020; Henry, 2020).

- $\quad$ Funds for the procurement of soap, hand sanitizer, and personal protective equipment (eg, gloves, masks) should be allocated at the most basic level.

- In several languages, educational resources should be disseminated to persons who are incarcerated and to staff assigned to answer any questions or concerns that occur. 
- All corrections personnel should be educated in the detection of symptoms of coronavirus and disease prevention.

- This begins with the update of intake forms to screen for individuals who meet COVID-19 testing specifications and access to rapid test results in detention settings.

- $\quad$ Partnership to access rapid research with local academic centers is encouraged.

- $\quad$ There should be dedicated spaces inside prisons to house individuals with confirmed or suspected COVID-19 who are not sufficiently sick to warrant hospital transfer with a schedule in place to move patients when they are not sick enough to warrant hospital transfer.

If more persons are to leave prisons and jails, the prison system should take action to minimize perceived threats. There are many other steps and services that are needed for those who are released from jail who are at risk of various issues, such as homelessness. In addition, it is essential to streamline access to and expand eligibility requirements for safety net services, including Medicaid and food stamps. It will take bold policy changes to resolve the COVID-19 pandemic's impacts across the U.S. Correctional System. Proactive action is required to mitigate the brewing tragedy set to unfold in the Nation's jails and prisons.

\section{References}

Abrams, D. (2020). COVID and crime: An early empirical look. U of Penn, Inst for Law \& Econ Research Paper, (20-49).

Akiyama, M. J., Spaulding, A. C., \& Rich, J. D. (2020). Flattening the curve for incarcerated populations-Covid-19 in jails and prisons. New England Journal of Medicine, 382(22),20752077.

Balassone, M. (2020, July 10). California Counties Keeping COVID-19 Emergency Bail Schedules California Courts Newsroom. California Courts Newsroom. Retrieved September 25, 2020, from https://newsroom.courts.ca.gov/news/california-counties-keeping-covid-19emergency-bail-schedules

Bentley, J. (2020, May 20). Norfolk County Jail Population Down 27 Percent Since Court Order. Patch. Retrieved October 07, 2020, from https://patch.com/massachusetts/foxborough/norfolkcounty-jail-population-down-27-percent-court-order 
Bradshaw, K. (2020, April 16). Hundreds of inmates have been released from San Mateo county jails in recent weeks. The Almanac Online. Retrieved October 1, 2020, from https://almanacnews.com/news/2020/04/16/hundreds-of-inmates-have-been-released-from-sanmateo-county-jails-in-recent-weeks

Bureau of Prisons. (2020a).COVID-19 Coronavirus. Retrieved from https://www.bop.gov/coronavirus/

Bureau of Prisons. (2020b).BOP implementing modified operations. Retrieved fromhttps://www.bop.gov/coronavirus/covid19_status.jsp

Burki, T. (2020). Prisons are "in no way equipped" to deal with COVID-19. Lancet (London, England), 395(10234), 1411.

Center for Disease Control. (2020, March 23). Interim guidance on management of Coronavirus Disease 2019 (COVID-19) in correctional and detention facilities. Retrieved From https://www.cdc.gov/coronavirus/2019-ncov/downloads/guidance-correctional-detention.pdf

Denney, A., \& Celona, L. (2020, March 17). Coronavirus in NY: Brooklyn DA to stop prosecuting 'low-level' offenses. New York Post. Retrieved October 12, 2020, from https://nypost.com/2020/03/17/coronavirus-in-ny-brooklyn-da-to-stop-prosecuting-low-leveloffenses/

Franco-Paredes, C., Ghandnoosh, N., Latif, H., Krsak, M., Henao-Martinez, A. F., Robins, M.,

Barahona, L.V., \&Poeschla, E. M. (2020). Decarceration and community re-entry in the COVID-19 era. The Lancet Infectious Diseases.

Freckelton, Q. I. (2020). COVID-19: Fear, quackery, false representations and the law. International Journal of Law and Psychiatry, 101611.

Hawks, L., Woolhandler, S., \& McCormick, D. (2020). COVID-19 in prisons and jails in the United States. JAMA Internal Medicine.

Henry, B. F. (2020). Social Distancing and Incarceration: Policy and Management Strategies to Reduce COVID-19 Transmission and Promote Health Equity Through Decarceration. Health Education \& Behavior, 1090198120927318.

Melamed, S., \& Newall, M. (2020, March 18). With courts closed by pandemic, Philly police stop low-level arrests to manage jail crowding. The Philadelphia Inquirer. Retrieved October 5, 2020, from https://www.inquirer.com/health/coronavirus/philadelphia-police-coronavirus-covidpandemic-arrests-jail-overcrowding-larry-krasner-20200317.html

Moneymaker, A. (2020, October 07). Trump Returns Home After Downplaying Disease, but Doctor Says He Isn't 'Out of the Woods'. The New York Times. Retrieved October 08, 2020, from https://www.nytimes.com/live/2020/10/05/world/covid-trump 
Moran, G. (2020, April 15). Hundreds released from jail under new bail rules, but prosecutors object to release of nearly 200 more. The San Diego Union-Tribune. Retrieved September 22, 2020, from https://www.sandiegouniontribune.com/news/courts/story/2020-04-15/court-and-jailreleases-draft

Nowotny, K., Bailey, Z., Omori, M., \& Brinkley-Rubinstein, L. (2020). COVID-19 Exposes need for progressive criminal justice reform.

Office of the Inspector General, US Department of Justice. (2020). The impact of an aging inmate population on the Federal Bureau of Prisons. Federal Sentencing Reporter, 32(5), 294-318.

Pascrell, B. (2020, September 03). Donald Trump vs. law enforcement: All the ways he's hurt policing in America as president. New York Daily News. Retrieved October 01, 2020, from https://www.nydailynews.com/opinion/ny-oped-donald-trump-vs-law-enforcement-20200903kvrq5fpj4vgythy4iypl2snsmi-story.html

Pohl, J. (2020, May 27). California jail population plummets during pandemic. Could this lead to long-term change? San Luis Obispo Tribune. Retrieved September 20, 2020, from https://www.sanluisobispo.com/news/california/article242900061.html\#storylink=cpy

Prison Policy Initiative. (2020a, June 25). Failing Grades: States' Responses to COVID-19 in Jails \& Prisons. Retrieved from https://www.prisonpolicy.org/reports/failing_grades.html

Prison Policy Initiative. (2020b, August 05). Jails and prisons have reduced their populations in the face of the pandemic, but not enough to save lives. Retrieved from https://www.prisonpolicy.org/blog/2020/08/05/jails-vs-prisons-update-2/

Prison Policy Initiative. (2020c, September 11). Response to the COVID-19 pandemic. Retrieved from https://www.prisonpolicy.org/virus/virusresponse.htm

Reinhart, E., \& Chen, D. (2020). Incarceration And Its Disseminations: COVID-19 Pandemic Lessons From Chicago's Cook County Jail: Study examines how arrest and pre-trial detention practices may be contributing to the spread of COVID-19. Health Affairs, 10-1377.

Reichert, J., \& Konefal, K. (2016, August 16). An Examination of Fear of Crime and Social Vulnerability in Chicago Neighborhoods. Retrieved May 09, 2020, from https://icjia.illinois.gov/researchhub/articles/an-examination-of-fear-of-crime-and-socialvulnerability-in-chicago-neighborhoods

Saad, L. (2020, April 16). In U.S., More Fear COVID-19 Illness Than Financial Harm. Gallup News. Retrieved October 10, 2020, from https://news.gallup.com/poll/308504/fear-covid-illnessfinancial-harm.aspx

Saloner, B., Parish, K., Ward, J. A., DiLaura, G., \& Dolovich, S. (2020). COVID-19 cases and deaths in federal and state prisons. JAMA, 324(6), 602-603. 
Scott, C. (2020, April 30). LA County Jail Population Reduced by 5,000 Since Outbreak. Spectrum New 1. Retrieved October 01, 2020, from https://spectrumnews1.com/ca/la-west/inside-theissues/2020/04/30/1-a--county-jail-population-reduced-by-5-000-since-beginning-of-coronavirusoutbreak

Smith, D. (2020, April 8). Judicial Council of California approves $\$ 0$ bail for low-level suspects. Sacramento Bee Logo. Retrieved September 20, 2020, from https://www.sacbee.com/news/coronavirus/article241817606.html

Souza, S. (2020, May 20). Plymouth County Jail Population Down 20 Percent Since Court Order. Yahoo News. Retrieved September 06, 2020, from https://news.yahoo.com/plymouth-county-jailpopulation-down-222304678.html

Souza, S. (2020b, May 20). Bristol County Jail Population Down 11 Percent Since Ruling. Yahoo News. Retrieved September 06, 2020, from https://news.yahoo.com/bristol-county-jailpopulation-down-224419817.html

Surprenant, C. (2020). COVID-19 and pretrial detention. Special Edition Policy Brief.

Wurcel, A. G., Dauria, E., Zaller, N., Nijhawan, A., Beckwith, C., Nowotny, K., \& BrinkleyRubinstein, L. (2020). Spotlight on jails: COVID-19 mitigation policies needed now.

Clinical Infectious Diseases.

Vera Institute of Justice. (2020, March 18).Guidance for preventive and responsive measures to Coronavirus for jails, prisons, immigration detention and youth facilities. RetrievedFromhttps://www.vera.org/downloads/publications/coronavirus-guidance-jails-prisonsimmigration-youth.pdf 